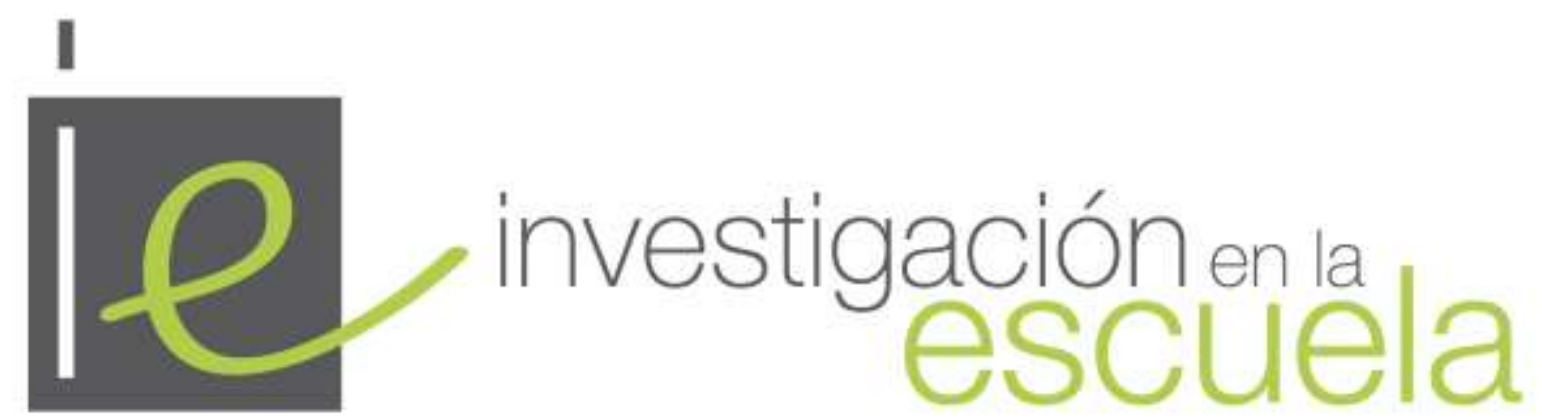

Revista internacional de investigación e innovación educativa

\title{
Estrategias lingüísticas para el tránsito a la competencia científica. Hablar y escribir para pensar en el aula de ciencias
}

\author{
Jordi Domènech Casal ${ }^{1,2}$
}

Institut de Secundària Marta Estrada (Granollers) ${ }^{1}$, Grupo LIEC, Departament de Didàctica de les Matemàtiques i les Ciències Experimentals ${ }^{2}$, Universitat Autònoma de Barcelona

España

Citación: Domènech Casal, J. (2019). Estrategias lingüísticas para el tránsito a la competencia científica. Hablar y escribir para pensar en el aula de ciencias. Investigación en la Escuela, 97, 47-63.

Resumen: El despliegue de nuevas metodologías competenciales para la enseñanza de las ciencias como la indagación y el aprendizaje basado en proyectos requiere el desarrollo de habilidades de razonamiento vinculadas a la capacidad de investigar, argumentar y desarrollar un discurso propio de las ciencias. Este cambio metodológico requiere atención a las necesidades y oportunidades de ámbito lingüístico asociadas. En este artículo se describen y analizan distintas intervenciones lingüísticas de escritura y la oralidad en relación con el desarrollo de la Competencia Científica y marcos metodológicos para la innovación en la enseñanza de las ciencias.

Palabras clave: "Escritura"; indagación; "competencia científica"; “oralidad".

Linguistic approaches for the transition to scientific competence. Writing and talking to think in Science classrooms

Página web: https://revistascientificas.us.es/index.php/IE

Artículo recibido: 05-03-2018

Facebook: / Revista Investigación en la Escuela IE

Revisiones recibidas: 12-03-2018

Aceptado: 09-04-2019 
Abstract: New methodologic frames as Inquiry and Project-Based Learning are being set in science classroom as a tool to the development of Scientific Competence. This requires the promotion of high order thinking skills related to the ability to investigate, argue and develop a scientific discourse. This methodologic change requires attention to specific linguistic needs and opportunities. In this article, we propose tools and frames for writing and talking in science classrooms regarding the development of Scientific Competence and methodologic frames for innovation in Science Education.

Key words: "Writing"; "scientific competence"; "talking"; "inquiry".

\section{Stratégies linguistiques pour la transition vers la compétence scientifique. Écrire et parler pour penser dans la classe de sciences}

Resumè: Les nouvelles méthodologies comme l'apprentissage des sciences par enquête et basé en projets sont développées comme utile pour le déroulement de la compétence scientifique. Cela fait nécessaire la promotion des habiletés de raisonnement liées aux processus d'investiguer, argumenter et développer un discours scientifique. Ce changement méthodologique entraine des besoins et opportunités linguistiques. Dans cet article, nous proposons des utiles et cadres pour écrire et parler dans les cours de sciences en égard du développement de la Compétence Scientifique et l'innovation dans l'Éducation Scientifique.

Mots-clés: "Écrire”; "parler”; "compétence scientifique”; "apprentissage basé en enquête”.

\section{Introducción}

La necesidad de un trabajo competencial en la enseñanza de las ciencias ha tenido impacto en el currículo y en las prácticas didácticas de aula, incorporando nuevas metodologías en las aulas de ciencias. Los trabajos prácticos de laboratorio incorporan cada vez más diseños investigativos en lugar de puramente demostrativos o instrumentales (Besson, Domènech-Casal, Goytia y Sánchez, 2012; Caamaño, 2011 y 2012; Hodson, 1994; Llewellyn, 2005). El trabajo en el aula abandona progresivamente la falacia de apropiación de modelos científicos mediante rituales memorísticos (distancias de los planetas, números atómicos o taxones) para enfocarse a su apropiación mediante la instrumentalización en el marco de dinámicas epistémicas, por ejemplo, mediante el aprendizaje basado en contextos, proyectos o controversias socio-científicas (Domènech-Casal, 2019a ; Sanmartí, 2016; Sanmartí, Burgoa y Nuño, 2011).

Estos enfoques implican el desarrollo de habilidades cognitivas de nivel alto, como la formulación de preguntas, el razonamiento inductivo-deductivo o el análisis crítico, fuertemente vinculados a habilidades cognitivo-lingüísticas (Lemke, 1997; Sanmartí, 2003). También implican una comprensión de la Naturaleza de la Ciencia y la capacidad de participar en el discurso epistemológico por el que la ciencia valida el conocimiento.

El lenguaje y el razonamiento están profundamente imbricados, de modo que el primero es necesario y supone una vía para el desarrollo del segundo (Lemke, 1997; Vygotsky, 2010). Por un lado, porque el lenguaje permite establecer las relaciones entre conceptos e ideas. Por el otro, porque la creación de conocimiento mediante el razonamiento es una actividad social que se produce en su comunicación. Por ello, la transición a espacios competenciales en la enseñanza de las ciencias necesita una transición paralela de las prácticas lingüísticas del aula de ciencias. En este sentido, se ha propuesto como estrategia el uso de andamios lingüísticos como apoyo (Sanmartí, 2003).

En Secundaria parte del profesorado de ciencias no es consciente de esta relación íntima entre lenguaje y competencia científica y de la importancia que este trabajo se lleve a cabo en el 
contexto de las clases de ciencias. Si bien se asume que la argumentación y formulación de preguntas investigables son habilidades clave en el desarrollo de la práctica científica, en la práctica el impulso competencial en estos aspectos es más difícil de apreciar y es habitual que se "externalicen" inútilmente- estos aspectos a materias lingüísticas o que su desarrollo no se planifique como parte del trabajo en el aula de ciencias.

En este artículo analizamos distintas dinámicas y recursos prácticos alrededor de la expresión oral y escrita aplicados en las aulas para identificar sus aportaciones teóricas al desarrollo de la competencia científica. Para hacerlo, hemos partido de aportaciones del ProyectoC3 sobre competencia científica (Domènech-Casal, 2016), el grupo de trabajo de profesorado EduWikiLab (Besson et al., 2015), y el grupo LIEC (Llengua i Ensenyament de les Ciències) de la Universitat Autònoma de Barcelona (Sanmartí, Izquierdo y García, 1999). Hemos agrupado las distintas propuestas y experiencias analizadas según el formato (escritura u oralidad) e identificamos para cada una de ellas los vínculos con distintas metodologías de enseñanza de las ciencias y aportaciones a la competencia científica.

\section{Escribir para pensar}

\section{Formular preguntas y elaborar conclusiones. Iniciadores para indagar}

Una de las vías que se ha propuesto para la enseñanza competencial de las ciencias es la enseñanza mediante la indagación. La Enseñanza de las Ciencias Basada en la Indagación (ECBI) (Caamaño, 2011; Hodson, 1994; Llewellyn, 2005) propone que el alumnado emule en primera persona el proceso de creación del conocimiento, siguiendo el ciclo indagador (observación, formulación de preguntas, hipótesis, análisis de datos, conclusión, formulación de un modelo y evaluación). Pero formular preguntas investigables es una habilidad científica compleja (Sanmartí y Márquez, 2012). Las primeras preguntas que suelen formular los estudiantes ante un fenómeno son del tipo “¿Por qué?” O “¿Cómo?”. “¿Por qué hay agua en el suelo?”. Estas preguntas son no investigables, pues no se puede construir una investigación a partir de ellas. El alumnado necesita un acompañamiento para poder interpelar fenómenos de forma productiva, por ejemplo, ayudándole a transformar las preguntas no investigables en preguntas investigables.

Una herramienta lingüística útil son los iniciadores de frase, fragmentos de texto que permiten comprender y orientar el propósito del texto y el razonamiento ofreciendo las palabras iniciales de la frase (Ferrés-Gurt y Domènech-Casal, 2018). Esto puede hacerse ayudando al alumnado a identificar los factores que pueden participar en sus preguntas iniciales y derivar de ellos preguntas investigables del tipo “¿Hay alguna diferencia si (altero este factor)?”; “¿Qué sucede si (elimino este factor)?”, “¿Hay alguna diferencia si apago la llave de la conducción subterránea de agua?”. Estas preguntas investigables tienen dos propiedades interesantes: llevan implícita una hipótesis que pretenden testar y son las que permiten diseñar experimentos y acotar paulatinamente con ellos el espacio de soluciones razonables a las preguntas iniciales no investigables (Domènech-Casal, 2014). Para su desarrollo, es útil el andamio IQ-R (Figura 1) que ha sido útil en distintas experiencias para ayudar al alumnado a plantear preguntas investigables y diseñar experimentos con sentido (Domènech-Casal y Ruiz-España, 2016).

Los iniciadores de frase también permiten acompañar al alumnado en el análisis de pruebas y la justificación para la elaboración de un modelo explicativo, como se hace para la historia geológica de un planeta en la actividad Gondwana Tales (Figura 1a, Domènech-Casal, 2015). 
a)
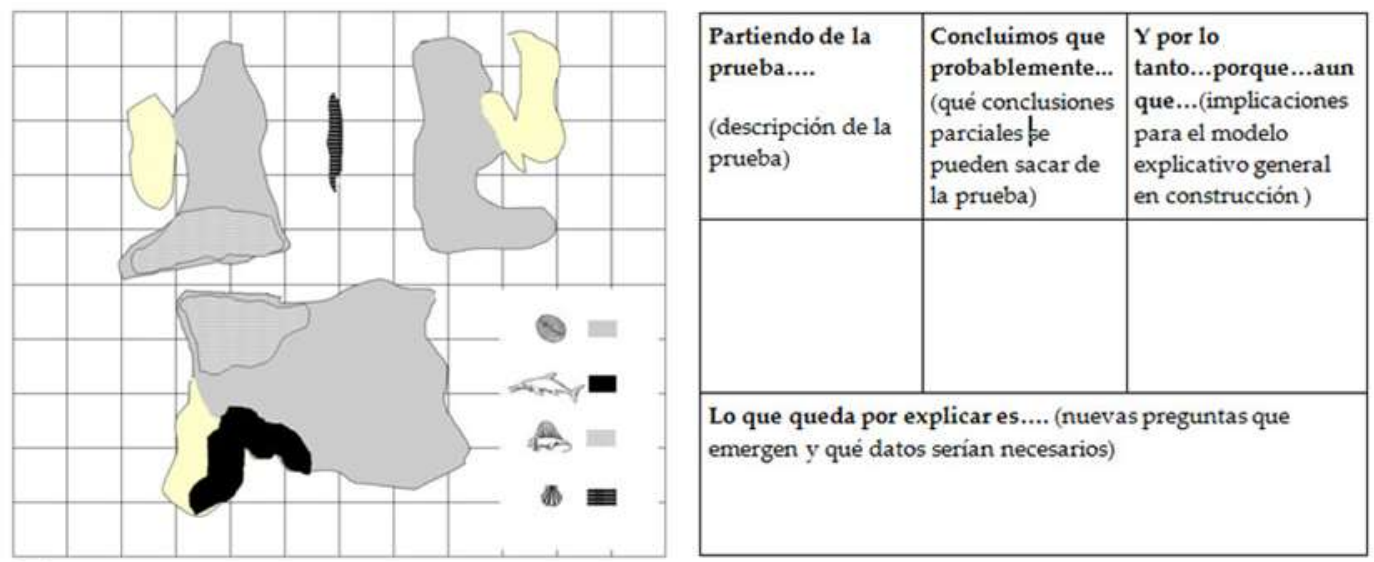

b)

\begin{tabular}{|c|c|c|}
\hline \multicolumn{3}{|c|}{ As we know that...some microorganisms are good and some harmful } \\
\hline \multicolumn{3}{|c|}{ Is there any difference in (think on factors)... their shapes? } \\
\hline \multicolumn{3}{|c|}{ This would allow us to test if...they are harmful because of their shape. } \\
\hline \multicolumn{3}{|c|}{ Experiment Design ...observing at a microscope: } \\
\hline Treatment A & Treatment B & Conclusion expectative \\
\hline Yaourth & Decomposed cheese & \\
\hline If....cells have a shape & $\begin{array}{l}\text { And...cells have the } \\
\text { same }\end{array}$ & $\begin{array}{l}\text { That would mean ... the shape is not causing a } \\
\text { microorganisms to be "good" or "bad". }\end{array}$ \\
\hline If...cells have a shape & $\begin{array}{c}\text { And...cells have a } \\
\text { different shape }\end{array}$ & $\begin{array}{l}\text { That would mean...the shape can have } \\
\text { something to do with "good" or "bad" } \\
\text { microorganisms. }\end{array}$ \\
\hline
\end{tabular}

Figura 1. a) Andamio con iniciadores de frase para el análisis de pruebas; b) andamio IQ-R con iniciadores de frase para el diseño de experimentos.

\section{Argumentar científicamente. Conectores gramaticales para enlazar conclusiones con la Ciencia}

Una parte importante del desarrollo de la competencia científica es la dimensión epistémica, que se ocupa de los medios que tiene la ciencia de validar el conocimiento científico. Esto implica no sólo la participación en liturgias de creación del conocimiento científico (congresos, debates, experimentos) sino también comprender la necesidad de establecer vínculos con el corpus científico consensuado por la comunidad científica. En ocasiones el alumnado percibe la ciencia como una mera acumulación de conclusiones, o asume que los datos de un solo experimento suponen ya creación de conocimiento científico, sin necesidad de conectar esas conclusiones con modelos de 
validez general. Esto es especialmente visible cuando al argumentar, los alumnos presentan dificultades en el uso de pruebas (Bravo, Puig y Jiménez-Aleixandre, 2009). En la argumentación científica, son necesarios distintos elementos, cada uno con un papel que es necesario evidenciar: las pruebas, la justificación... (Jiménez-Aleixandre, 2010; y Trinidad, 2010). Toulmin, Rieke y Janik (1984) proponen como elementos fundamentales los datos, la justificación, la garantía y las conclusiones. En particular, la garantía se refiere al marco consensual al que se acoge la relación entre los datos y la justificación, y podemos asimilarla a la necesidad de conexión de conclusiones con modelos de validez general que mencionamos en el párrafo anterior.

Tabla 1

Andamio parte del taller de argumentación cientifica del proyecto C3. Disponible en https:/ / app.box.com/s/a76pycwngmb6wtiiov72

\begin{tabular}{lll}
\hline Dado que... & DATOS & $\begin{array}{l}\text { Cosas que se observan y que en principio son } \\
\text { compartidas por todos sin discusión } \\
\text { "Dado que la combustión genera dióxido de } \\
\text { carbono," }\end{array}$ \\
\hline Y... & JUSTIFICACIÓN & $\begin{array}{l}\text { Relación entre lo que observamos y lo que } \\
\text { pretendemos concluir } \\
\text { "...y los coches queman combustible" }\end{array}$ \\
\hline$\ldots$ general que... & $\begin{array}{l}\text { Norma general aceptada por todos que da solidez a } \\
\text { la justificación. Define un contexto de validez en la } \\
\text { que la justificación se cumple necesariamente. } \\
\text { "Y se cumple de forma general que el dióxido de } \\
\text { carbono promueve el efecto invernadero" }\end{array}$ \\
\hline Entonces... & CONCLUSIÓN & $\begin{array}{l}\text { Conclusión que se defiende. } \\
\text { "Entonces, los coches son en parte contribuye al } \\
\text { efecto invernadero" }\end{array}$ \\
\hline A menos que... & REFUTACIÓN & $\begin{array}{l}\text { Define un contexto en que la justificación dejaría de } \\
\text { tener validez. } \\
\text { "A menos que se desarrollen coches eléctricos } \\
\text { impulsados con energías que no generen dióxido de } \\
\text { carbono" }\end{array}$ \\
\hline
\end{tabular}

El desarrollo de estos elementos puede promoverse mediante apoyos (Ripoll, Chasco, Azcárate, 2013). Los conectores gramaticales permiten al alumnado establecer y comprender las relaciones de ideas entre distintas partes de un razonamiento (y un texto) en construcción. Cada conector ("por lo tanto, por otro lado, aun así, en cambio") promueve un tipo de razonamiento, de modo que pueden ser propuestos como apoyos para que el alumnado desarrolle textos (y razonamientos). La Tabla 1 muestra un ejemplo de andamio que incluye conectores gramaticales y ejemplos. Un primer abordaje del trabajo en argumentación es ofrecer al alumnado argumentaciones simples desordenadas para que las ordenen, con la ayuda de la tabla para, a continuación, ofrecer algunas en las que faltan partes de la argumentación. Usualmente, las argumentaciones iniciales del alumnado no suelen tener Garantías ni Refutaciones. Estos dos elementos son muy importantes epistemológicamente, porque determinan, respectivamente, el marco común desde el que argumentamos (los consensos científicos) y el grado de certidumbre de nuestras conclusiones. En experiencias con alumnado de $4^{\circ}$ de ESO, pedir al alumnado que añada 
garantías y refutaciones a sus argumentaciones iniciales ha sido de utilidad para mejorar la calidad de las argumentaciones, su capacidad de generar consensos y desarrollar el concepto de garantía como consenso de la comunidad científica (Domènech-Casal, 2019a). Estrategias similares han sido propuestas por otros autores en relación a la justificación (Custodio, Márquez y Sanmartí, 2015).

\section{Habitar el discurso epistémico. Estructurar el razonamiento mediante Géneros textuales científicos}

La ciencia como disciplina tiene sus propios géneros textuales (artículos científicos, posters, ensayos...) que deben ser aprendidos en paralelo con las razones epistemológicas que los estructuran. Por ejemplo, en los artículos científicos, la estructura (Introducción, Material y Métodos, Resultados y Discusión y Conclusiones) establece que Resultados y Conclusiones estén separados para comunicar una pretensión de atemporalidad y objetividad en los primeros. Asimismo, el Material y Métodos antes que estos dos apartados obedece a la secuencia cronológica de la investigación científica, y usa la voz pasiva "se hicieron", "fueron medidos" para transmitir la idea de un método reproducible, independiente del actor. También en los ensayos científicos los apartados estándar intentan separar los datos de sus interpretaciones. El trabajo con estos géneros científicos es una potente herramienta que permite al alumnado escribir (y pensar) de la forma en que se escribe (y se piensa) la ciencia, y puede desarrollarse con andamios - plantillas para los textos- que contengan descripciones de funciones de cada apartado en el discurso, iniciadores de frase y textos de ejemplo (Figura 2) (Domènech-Casal, 2013; 2017).

a)

\begin{tabular}{ll}
\hline INTRODUCCIÓN & Esta investigación trata... Sobre este tema, se sabe que... \\
& Nuestro objetivo es saber si.... Nuestra hipótesis es... \\
\hline MATERIAL Y MÉTODOS & $\begin{array}{l}\text { El procedimiento se divide en... En primer lugar se ha.... en } \\
\text { último lugar... Las muestras han sido... Se ha medido... }\end{array}$ \\
\hline RESULTADOS & Como vemos en el gráfico $1 . .$. Se aprecia \\
& que... Comparativamente... Hay diferencia/no hay diferencia \\
& entre... \\
\hline DISCUSIÓN Y & Nuestros resultados indican que... porque...por lo tanto... \\
CONCLUSIONES & Como futuros experimentos... \\
\hline
\end{tabular}

b)

\begin{tabular}{ll}
\hline Planteamiento y datos & $\begin{array}{l}\text { La situación/dilema/ problema es que... En el momento actual, se sabe } \\
\text { que... }\end{array}$ \\
\hline $\begin{array}{l}\text { Modelos científicos } \\
\text { implicados }\end{array}$ & $\begin{array}{l}\text { Desde un punto de vista científico, se ha demostrado que... No se } \\
\text { tienen evidencias de... }\end{array}$ \\
\hline Argumentos & Por un lado...Pienso que...puesto que... \\
\hline Contra-argumentos & Por otro lado... No apoyo...dado que... \\
\hline Conclusión & En consecuencia,...la solución para este dilema....
\end{tabular}

Figura 2. Fragmentos simplificados de andamios para la escritura de artículos científicos (a) y ensayos científicos (b). Disponibles en: https://sites.google.com/a/xtec.cat/c3/home y https://sites.google.com/site/cscframe/home. 
Las habilidades cognitivo-lingüísticas como describir, justificar, argumentar, encuentran en los artículos y ensayos científicos no sólo un contexto relevante para su desarrollo, sino que además estas habilidades y sus correspondientes tipologías textuales (texto descriptivo, narrativo, argumentativo,...) tienen un propósito epistémico: los resultados se describen, porque deben poder ser reinterpretados, los materiales y métodos se narran porque son pasos de un proceso, las conclusiones se argumentan, porque pretenden asentar una proposición en base a las pruebas obtenidas. Esto implica asociar los distintos elementos de estos textos (estructura, conectores gramaticales) al propósito de los textos (objetividad, relación con un modelo científico,...). El uso de estos andamios permite al alumnado mejorar no sólo su redacción de textos científicos, sino también su capacidad de desarrollar investigaciones y razonamientos científico (Domènech-Casal, 2013; 2017).

\section{Hablar para comprender}

En relación a la expresión oral, si bien existen actividades que incluyen expresión oral en el aula de ciencias, no toda ella es trabajo científico. Por poner un ejemplo, son ya cada vez más habituales las presentaciones orales con ayuda de un fichero de presentación, realizadas bajo un marco evaluativo común a todas las materias y que se orienta a aspectos comunicativos no vinculados a las ciencias (tamaño y tipo de letra, nivel de voz, dicción,...). La expresión oral puede encarnarse en las ciencias en varias dinámicas en las que el análisis de un fenómeno implica un diálogo con los modelos científicos, con las evidencias y con los compañeros.

\section{Hablar con y de fenómenos. Conversación dialógica}

Un ejemplo son las conversaciones dialógicas y modelizadoras alrededor de un fenómeno que provoca una disonancia cognitiva (Márquez y Pedreira, 2005). Estas discusiones y la búsqueda de un sentido acaban generando la necesidad de un léxico que emerge para definir los conceptos nacientes (Figura 3) (Martín, 2013; Sanmartí, Izquierdo y García, 1999).

No siempre es sencillo promover la participación del alumnado, algo necesario si queremos detectar las concepciones alternativas desde las que a menudo interpelan los fenómenos. Las "prácticas mudas" son una propuesta de utilidad en este sentido. Se basan en una idea sencilla: el ritual académico habitual en los trabajos prácticos de laboratorio es que el profesor/a explica a los alumnos el propósito de la práctica y los pasos a seguir, y los alumnos escuchan y aplican el procedimiento propuesto. Se cambia el proceso: el profesor/a representa los objetivos y procedimiento sin hablar, por mímica y señalando términos de léxico escritos en la pizarra. El alumnado discute oralmente el significado de cada parte de la representación, proponiendo un significado, a lo que el profesor/a, siempre mediante mímica, asiente o niega. De ese modo, se ha visto en distintas experiencias (Besson et al., 2015) que el docente recibe información acerca de lo que están entendiendo los alumnos, y éstos tienen un papel activo e instrumentalizan el léxico ya desde el primer momento de la práctica.

P.-Hemos pesado en la balanza este globo vacío, lo he llenado de aire, he hecho un nudo y volveré a pesarlo. ¿Cuál es vuestra predicción? ¿Pesará igual, más o menos? A1.Pesará lo mismo. A2.No, más. A1. No, lo mismo. A2. Más.
P. ¿Por qué pensáis que pesará más o lo mismo?

A1.Pesará lo mismo, porque el aire no pesa. A2. Sí que pesa, pero poco.

P. Pero cuando lo peso vacío, por encima del globo hay aire. ¿Qué os sugiere eso? 
A1. ¿Ves? Pues pesará lo mismo, porque aunque el aire pese, da lo mismo que esté dentro que fuera del globo.

P.-Entonces, estamos de acuerdo en que no debería cambiar, ¿verdad? [lo pesa]. Da un par de miligramos más. ¿Qué está ocurriendo? A1. Tendría que pesar lo mismo. A2. Es porque el aire dentro del globo está "más apretado" que fuera.

P. ¿Qué quieres decir con eso?
A2. Que al apretarlo queda un aire que tiene más cosa, i cuanta más cosa hay, más pesa. P.-Entonces, ¿los globos de la feria, que van hacia arriba?

A1.Es porque es un aire "poco apretado". Hay aires que pesan menos porque son menos pesados.

P. De acuerdo. A eso de que la masa (no "la cosa") esté "más apretada" lo llamaremos que es más densa, tiene una densidad mayor.

Figura 3. Reconstrucción de una conversación dialógica alrededor de un experimento sobre la densidad.

\section{Debatir y cartografiar significados. Controversia y debate}

El trabajo con controversias socio-científicas es un espacio privilegiado para el desarrollo de la competencia científica. Las controversias socio-científicas son cuestiones socialmente vivas con vínculos conceptuales con la ciencia y valores personales y morales (Díaz y Jiménez-Liso, 2012; Kolstø, 2001). Se orientan a la resolución de un problema o pregunta, y conectan con distintos ámbitos temáticos (salud, innovación tecnológica, sostenibilidad,...) y pueden tener distintos alcances: personal (¿Qué coche me compro?) o social (¿Deberíamos prohibir el diésel?) (Díaz y Jiménez-Liso, 2012). Su uso en el aula promueve la comprensión de los modelos científicos (cambio climático, ciclos biogeoquímicos,...) mediante su instrumentalización en la resolución del problema (Domènech-Casal, 2017; España y Prieto, 2010; Sadler y Zeidler, 2005). Más allá de esa vertiente conceptual y de otros aspectos procedimentales (p.e. desarrollo de habilidades investigadoras) o epistémicos (p.e. argumentar científicamente), la competencia científica implica la capacidad de tomar decisiones en contextos participados por la ciencia. En ese sentido, consideramos que las controversias socio-científicas son un contexto necesario para el desarrollo de la competencia científica, si bien en su aplicación en el aula genera espacios lingüísticos que deben ser atendidos. Uno de ellos es el debate, un género textual que requiere de un trabajo específico (Solbes, Ruiz y Furió, 2010). La creación de una visión del debate como espacio constructivo y exploratorio se ve obstaculizada por referentes televisivos, conversaciones disputativas en las que prima el desacuerdo y la toma de decisiones individual y en los que los participantes no dudan en recurrir a falacias con el objetivo de "ganar". Otros autores consideran que es necesario previamente generar en el alumnado modelos de diálogo en el que los participantes no se ocupan de proteger sus intereses o identidades, sino de conseguir una mejor comprensión del tema (Farró, Lope, Marbà y Oliveras, 2015; Lope y Farró, 2018; Vilà, y Castellà, 2012). Esos modelos de debate suponen un refuerzo del modelo epistémico de las ciencias, por lo que no pueden ser conversaciones disputativas ni meramente acumulativas (en que se yuxtaponen intervenciones sin un esfuerzo consciente de los participantes por estructurarlas para dar sentido). El modelo de conversación exploratoria implica que los interlocutores abordan críticamente pero constructivamente las intervenciones propias y de otros en un esfuerzo consciente de ampliar el paisaje de lo conocido, orientando la conversación a una cartografía de los significados. Esto hace de este tipo de conversación una metáfora de la construcción del conocimiento científico, pero requiere herramientas para conseguirlo. Entre ellas, varios autores proponen el uso de tarjetas con distintos objetivos (Figura 4). 

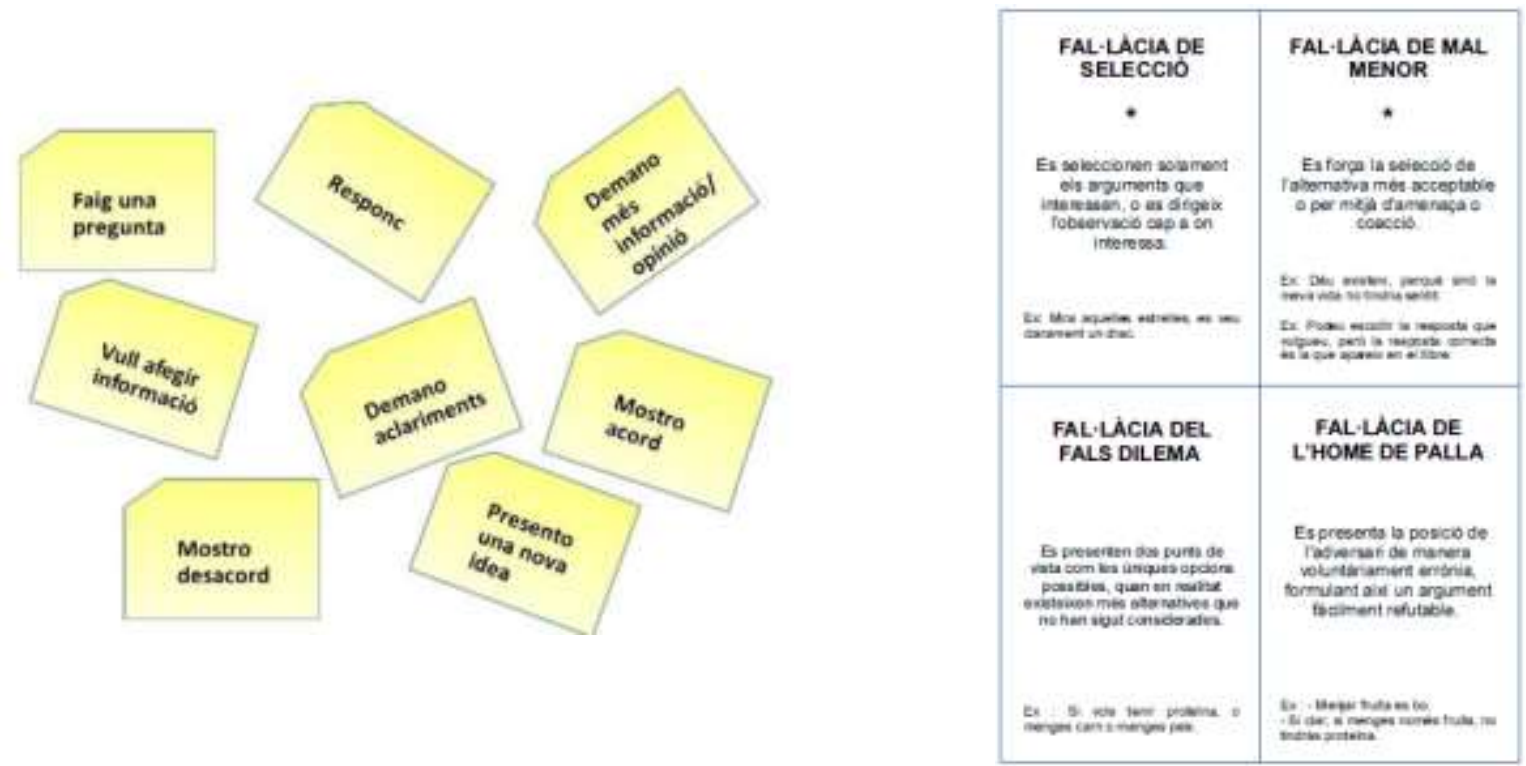

Figura 4. a) Tarjetas de participación, extraído de Farró et al. (2015); b) Tarjetas de Falacias, (Calamars Gegants, 2017).

Las tarjetas conversacionales (Figura 4a) son tarjetas con distintos tipos de participación (“Añadir una información”, "Pedir una aclaración”, "Comunicar desacuerdo",...) que el alumnado debe esgrimir para participar en el debate. Estas estrategias conversacionales y han resultado útiles en distintas experiencias para promover un debate constructivo (Lope y Farró, 2018). Las tarjetas de Falacias (Figura 4b, Calamars Gegants, 2017) han sido desarrolladas como herramienta para que el alumnado identifique falacias argumentativas al aparecer éstas en el debate, de modo que la escucha de las participaciones es mucho más atenta al significado e implicaciones en el marco del debate. Si bien en su aplicación es complejo para el alumnado identificar "en tiempo real" las falacias, su estudio ha resultado útil a alumnado de $3^{\circ}$ de ESO para comprender que los razonamientos pueden y deben analizarse (Domènech-Casal, 2019a).

\section{Construir conocimiento en el laboratorio y fuera de él: seminarios de laboratorio y congresos científicos como género oral en las ciencias}

Las sesiones de posters en congresos científicos y seminarios de laboratorio son espacios de comunicación oral cuya estructura y rituales están conectados con el modo de construir conocimiento de la ciencia. En las sesiones de posters, un investigador se presta a discutir sus conclusiones con otros investigadores con la ayuda de un póster como soporte para mostrar las evidencias y análisis realizado a partir de las mismas. En los seminarios de laboratorio, varios investigadores de un mismo grupo de trabajo se reúnen para discutir resultados parciales o investigaciones en marcha con el objetivo de recabar ideas o propuestas para seguir avanzando.

En la actividad "Seminarios de investigación" (Besson et al., 2015) se invitó al alumnado a participar como investigadores en seminarios de laboratorio a partir de investigaciones realizadas por ellos. Como ejemplo de uno de esos seminarios ("Tropismos en las plantas") cada pequeño equipo de dos alumnos diseñaba su experimento para comprobar/descartar la existencia de distintos tropismos en plantas (luz, agua, arena, sal...) y presentaba de manera informal a lo largo de la investigación sus progresos. En la presentación, basada únicamente en fotografías de los experimentos y explicación oral, los demás participantes podían interrumpir para pedir aclaraciones, 
hacer propuestas o discrepar en interpretaciones (Figura 5). Durante la sesión, el profesor anota las intervenciones relevantes científicamente (mejoras en diseño de experimentos, nuevas conclusiones inesperadas, uso de términos específicos como "hipótesis", "tratamiento", "control”...) y al final del seminario comunicaba al alumnado su análisis de la conversación.

El formato de sesión de posters se puede desarrollar como interacción entre dos grupos clase que hayan desarrollado investigaciones distintas (Álvarez et al., 2016), o como congreso científico al que acudan también científicos del mundo exterior a la escuela. Este tipo de comunicación oral, permite el trabajo ágil y repetido de la interpretación y argumentación a partir de evidencias, una parte fundamental de la competencia científica. En el congreso sobre evolución de los Caminalcules -seres vivos imaginarios- realizado en varios centros educativos, por ejemplo (Domènech-Casal, 2016), la presencia de científicos reales propició una situación comunicativa de alto interés: los alumnos, expertos en Caminalcules, discutiendo la interpretación de evidencias evolutivas con científicos profesionales con los que sólo podían comunicarse en términos de léxico científico (Figura 5).

Ambos tipos de eventos (Congresos científicos y Seminarios de laboratorio) implican un trabajo en comunicación oral con dos Componentes básicos: 1) estructura del discurso: se identifica la pregunta de investigación, las evidencias recabadas y se discute con el interlocutor la interpretación de las evidencias, con ayuda de conectores gramaticales adecuados: por lo tanto, en consecuencia...; 2) estructura de la situación comunicativa: en ambas situaciones, participan tres partes: el experto, las evidencias y el interlocutor, que se comunican de forma ágil a través del modelo científico. Es importante al trabajar estos formatos hacer a los alumnos conscientes de estas dos Componentes.

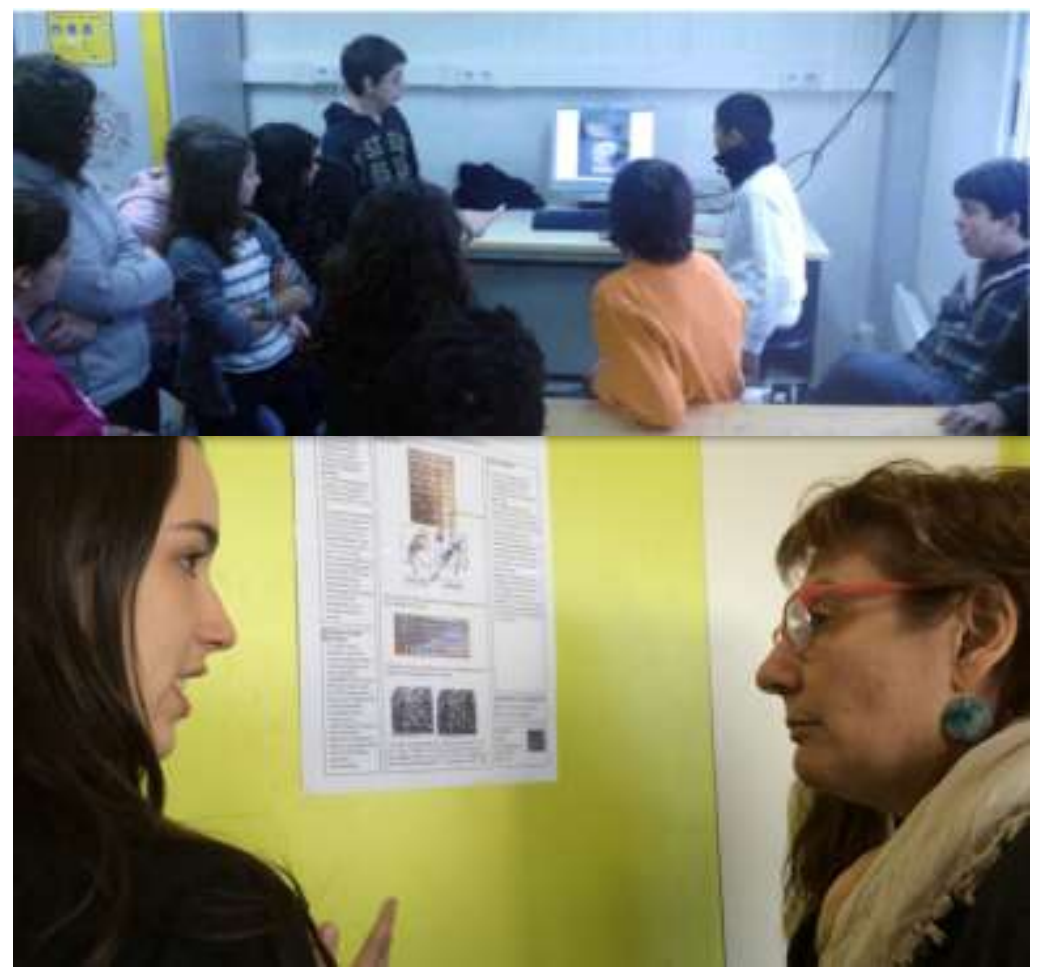

Figura 5. Imágenes de un seminario de laboratorio y un congreso científico escolar desarrollados, respectivamente, por alumnado de $2^{\circ}$ y $4^{\circ}$ de ESO. 


\section{Programar y evaluar para la competencia científica}

Las necesidades y posibilidades lingüísticas deben ser tenidas en cuenta al programar y evaluar unidades didácticas de ciencias. En particular, esto implica tener en cuenta dos aspectos: 1) E1 lenguaje como herramienta: ¿Qué herramientas lingüisticas necesita mi alumnado para conseguir los objetivos de aprendizaje de esta unidad didáctica?; 2) El lenguaje como objetivo: ¿Qué parte de los objetivos de aprendizaje de esta unidad didáctica son de naturaleza lingüistica? Además, debe preverse cómo secuenciar las distintas modalidades lingüísticas y prever qué apoyos serán necesarios.

\section{La identificación y comunicación de objetivos de aprendizaje}

¿Qué habilidades/capacidades lingüísticas están implicadas en los objetivos de aprendizaje? ¿Qué necesitaran saber hacer los alumnos/as? ¿Cómo les enseñaremos? Es importante consultar el currículum, especialmente los criterios de evaluación. Éstos suelen iniciarse con "Describir..." "Justificar..." "Argumentar...", habilidades lingüísticas que, junto con el léxico deben ser parte del listado de objetivos de aprendizaje. Concretar estos objetivos de forma explícita, evidenciando de forma clara la naturaleza lingüística de algunos de ellos, debería ser un primer paso fundamental. Para ello pueden ser de ayuda los KPSI (Knowledge and Prior Study Inventory) (Young y Tamir, 1977) (Tabla 5), andamios que permiten comunicar al alumnado los objetivos de aprendizaje para que participe del proceso de aprendizaje y autoevalúe su nivel de conocimiento para cada uno de ellos al inicio y final de la secuencia.

Tabla 2

Ejemplo de Ficha KPSI

Puntuar del 1 al 4 tu nivel de conocimiento

Inicio Final

Usar el ciclo del agua para analizar fenómenos

Conocer las fuentes de contaminación del agua

Tomar decisiones para un uso sostenible del agua

Diseñar experimentos

Sacar conclusiones de datos

Saber escribir una justificación de medidas de gestión del agua

Representar datos en gráficos y describirlos

oralmente

Usar adecuadamente el léxico específico para

describir problemáticas medioambientales

\section{La secuenciación de actividades}

En la secuenciación de actividades es fundamental que las distintas propuestas tengan un sentido dentro de un marco general y prever los apoyos o andamios didácticos que pueden necesitar los alumnos. Por lo que respecta al primer punto, combinar en una secuencia didáctica distintas modalidades comunicativas permite acercarse a contextos reales (pues raramente implican una sola modalidad), usar una modalidad comunicativa como acceso a otra (aprender a escribir leyendo, o aprender a hablar escribiendo) y ofrecer distintas "ventanas" de entrada a lo largo de la secuencia 
para alumnado con dificultades con alguna modalidad comunicativa. Como ejemplo, el marco CSCFrame (Domènech-Casal, 2017) propone el trabajo con controversias socio-científicas orientado a la escritura de un ensayo, en una secuencia estructurada en tres etapas: 1) proponer un dilema y LEER críticamente distintas fuentes; 2) Establecer un DEBATE ORAL sobre el dilema y la aportación que supone cada fuente; y 3) posicionarse individualmente en la ESCRITURA de un ensayo de ámbito científico (Figura 6).

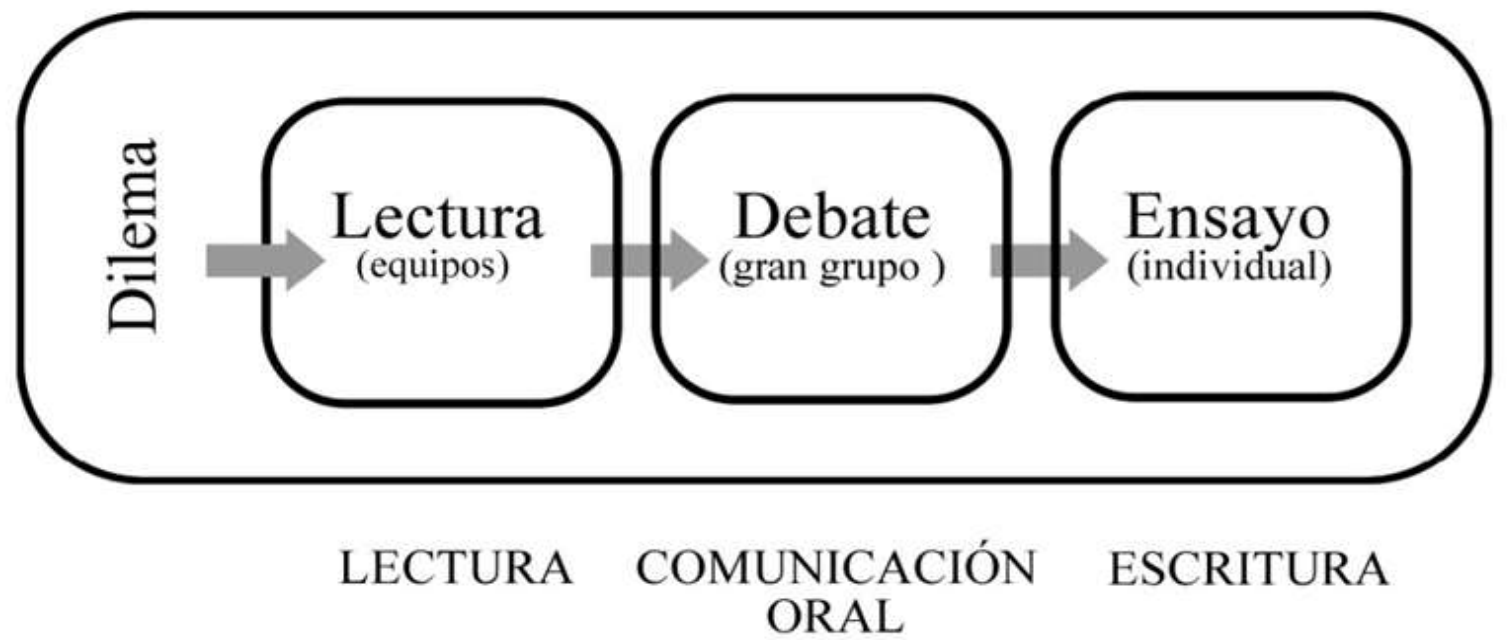

Figura 6. Esquema de concatenación de modalidades con sentido en CSCFrame. Extraído de https:// sites.google.com/site/cscframe/home

A lo largo de la secuencia, o, como mínimo, en una síntesis final, debe hacerse un trabajo explícito del léxico científico. En muchas ocasiones el acceso al léxico científico es dificultado por interferencias con el lenguaje coloquial: el uso de determinados términos en expresiones del lenguaje coloquial como "consumir o ahorrar energía" o "perder peso" dificulta su uso en su sentido científico (la energía no se consume, y perder peso no es lo mismo que perder masa). Además, los términos de léxico científico son complejos, pues provienen en muchas ocasiones de neologismos o composiciones, o bien de nominalizaciones. En consecuencia, muchos alumnos participan en las situaciones comunicativas del aula de ciencias usando anti-léxico: perífrasis o lenguajes metafóricos que substituyen el léxico, ofreciendo versiones poco sofisticadas de los modelos científicos a los que refieren: "lo pesado que es algo" es un término insuficiente para hablar de densidad, porque la relación masa/volumen no depende del peso.

Más allá de los glosarios o la memorización, las actividades orientadas a la categorización y establecimiento de relaciones con otros términos son de utilidad. En este sentido, la propuesta de otros autores, el denominado modelo Frayer (Figura 7) (Frayer, Frederick y Klausmeier, 1969) propone al alumnado un trabajo de análisis y formalización en equipo o como grupo- clase alrededor de los términos de léxico fundamentales de una unidad o secuencia didáctica.

En lo que respecta a los andamios didácticos, además de los distintos tipos propuestos, de tipo estático (KPSI, plantillas, rúbricas, iniciadores,...) o dinámico (trabajo en equipo o modelización por el docente) conviene tener presente: 1) los andamios se proponen como apoyo temporal, no para generar una dependencia en el alumnado, sino con el objetivo final de retirarlos paulatinamente y que puedan desarrollar la tarea sin ellos; 2) los andamios deben ajustarse a las capacidades del 
alumno/a: cada alumno usa los apoyos que necesita, ni más ni menos; 3) la evaluación del profesor o de compañeros es también un andamio: las producciones del alumnado deben ser revisadas y rehechas más de una vez si es necesario, dando varias oportunidades mientras el alumno/a siga aprendiendo. Por ejemplo, en la aplicación de una plantilla para la escritura de artículos de investigación en el laboratorio retiraremos paulatinamente los apoyos lingüísticos para que el alumnado llegue a escribir (y pensar) de forma autónoma sus propios artículos científicos (Domènech-Casal, 2013).

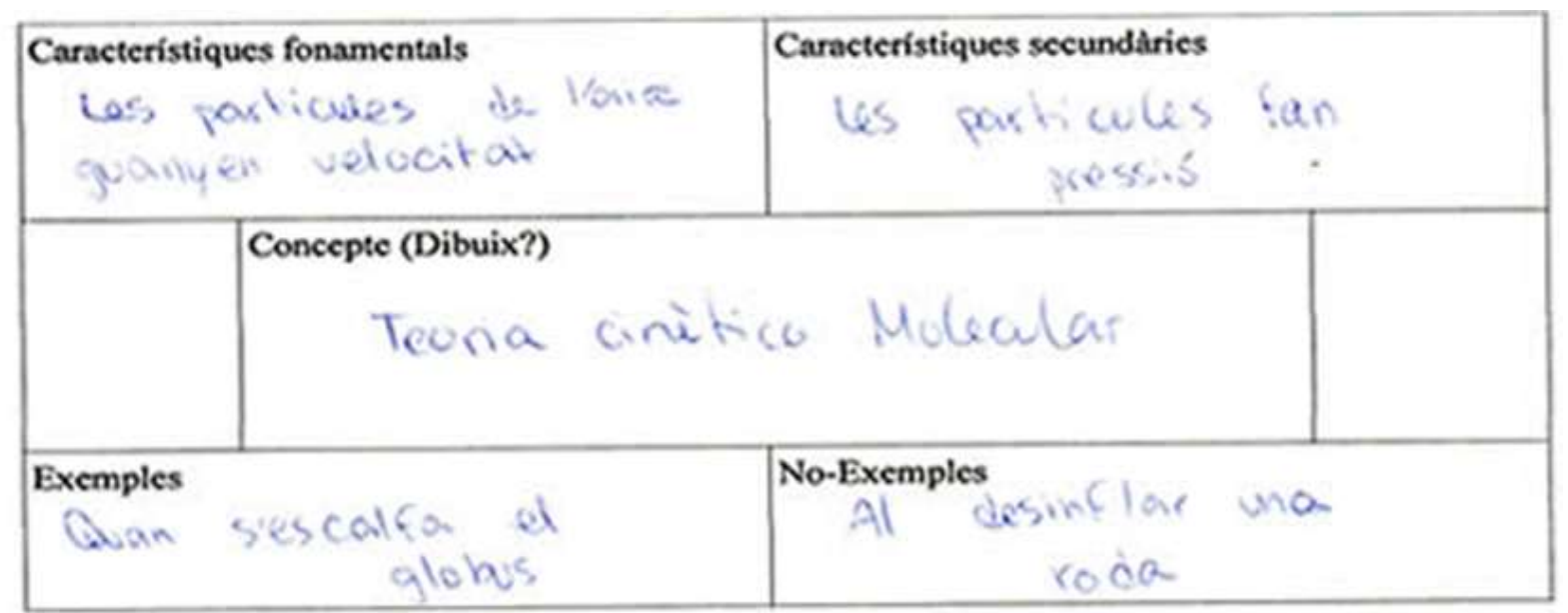

Figura 7. Estructura de un modelo Frayer para el trabajo específico del léxico. Incluye 5 apartados: Concepto, Características Fundamentales, Características secundarias, Ejemplos, No Ejemplos. Extraído de Domènech-Casal (2018).

Conviene tener en cuenta que determinados andamios pueden limitar la creatividad del alumnado (por ser excesivamente cerrados) o generar desconcierto (por ser excesivamente abiertos) y que el punto de equilibrio puede ser distinto para cada alumno/a. Así mismo, la adaptación de textos y formatos puede también ser una ayuda a prever en el desarrollo de una secuencia didáctica. En todo caso, conviene evitar simplificar el léxico o despojar los textos de los elementos contextuales (cabecera del periódico, cuenta de Twitter,...) que permiten completar su sentido y veracidad y limitar las adaptaciones a disminuir su extensión o aumentar la cantidad o variedad de elementos de apoyo (imágenes, gráficos).

\section{Conclusiones}

El desarrollo de la competencia científica implica habilidades de razonamiento y práctica de dinámicas epistémicas que requieren una mirada lingüística al modo que tiene la ciencia de crear conocimiento (Hernández y Hernández, 2011). Este trabajo debe hacerse desde las áreas científicas porque sólo en el marco de géneros textuales y contextos epistémicos científicos pueden desarrollarse de forma significativa para las ciencias habilidades y competencias la formulación de preguntas investigables, la elaboración de conclusiones a partir de datos, o la argumentación en conexión con los modelos científicos y contextos reales. Las propuestas presentadas en este artículo sobre escritura y oralidad son complementarias con otras propuestas alrededor de la lectura como indagación que describimos en una publicación reciente (Domènech-Casal, 2019b).

Para el trabajo con los distintos marcos propuestos puede ser de interés impulsar a nivel de centro educativo la toma de acuerdos en distintas formas a nivel de departamento de ciencias (andamios compartidos, listados de léxico clave, distribución de géneros textuales por cursos,...) y 
con el departamento de lengua para establecer colaboraciones (Trujillo, 2015) que superen los tradicionales acuerdos de restar puntos por faltas de ortografía. Este artículo pretende ser una invitación al profesorado de ciencias a promover la competencia científica mediante herramientas lingüísticas. Existe un trabajo lingüístico que es necesario (y posible) hacer desde las ciencias para un correcto despliegue de la competencia científica. La decisión a tomar no es si hacemos o no un trabajo lingüístico en el aula de ciencias. La decisión a tomar es si los alumnos lo hacen con nuestra ayuda, o lo hacen sin ella.

\section{Agradecimientos}

Al profesorado y alumnado de los institutos Institut Marta Mata, de Montornès del Vallès, Institut de Vilanova del Vallès, Instituto Marta Estrada, de Granollers y del grupo de trabajo Calamars Gegants, por su colaboración en el desarrollo y aplicación de los marcos propuestos. Reflexiones incluidas en este artículo se enmarcan en la investigación metodológica del grupo de investigación consolidado LICEC (referencia 2014SGR1492) por AGAUR y financiado por el Ministerio de Economía y Competitividad (referencia EDU2015-66643-C2-1-P).

\section{Referencias}

Álvarez, J.A., Domènech-Casal, J., Garrote, A., Gasco, J., Oliveros, C. y Rodríguez, L. (2016). Investiguem i ens comuniquem científicament: una proposta de centre com a dinamització de la Competència Científica. Revista Ciències, 31, 12-20.

Besson, I., Domènech-Casal, J., Goytia, E. y Sánchez, N. (2012). EduWikiLab : la creació d’un espai $\mathrm{col} \cdot$ laboratiu sobre treballs pràctics al laboratori i al taller. Revista Ciències, 23, 15-20.

Besson, I., Goytia, E., Miró, M. y Domènech, J. (2015). Pràctiques mudes, congressos científics, seminaris de recerca $\mathrm{i}$ altres dinàmiques científiques d'oralitat al laboratori i a l'aula. Revista Ciències, 29, 15-24.

Bravo, B., Puig, B. y Jiménez-Aleixandre, P. (2009). Competencias en el uso de pruebas en argumentación. Educación Química, 137-142. doi: 10.1016/S0187-893X(18)30020-X

Caamaño, A. (2011). Contextualización, indagación y modelización. Tres enfoques para el aprendizaje de la competencia científica en las clases de química. Aula de Innovación Educativa, 207, 17-21.

Caamaño, A. (2012). ¿Cómo introducir la indagación en el aula? Los trabajos prácticos investigativos. Alambique: Didáctica de las Ciencias Experimentales, 70, 83-91.

Calamars Gegants (Grupo de Trabajo de Profesorado) (2017). Tarjetas de falacias. Recuperado de http://www.betacamp.cat/kemestaskontainer/

Custodio, E., Márquez, C. y Sanmartí, N. (2015). Aprender a justificar científicamente a partir del estudio del origen de los seres vivos. Enseñanza de las Ciencias, 33(2), 133-155. doi: $10.5565 / \mathrm{rev} /$ ensciencias.1316

Díaz, N. y Jiménez-Liso M. R. (2012). Las controversias sociocientíficas: temáticas e importancia para la educación científica. Revista Eureka sobre Enseñanza y Divulgación de las Ciencias, 9(1), 54-70. doi: 10.25267/Rev_Eureka_ensen_divulg_cienc.2012.v9.i1.04

Domènech-Casal, J. (2013). Secuencias de apertura experimental y escritura de artículos en el laboratorio: un itinerario de mejora de los trabajos prácticos en el laboratorio. Enseñanza de las Ciencias, 31(3), 249-262. doi: 10.5565/rev/ec/v31n3.851

Domènech-Casal, J. (2014). Indagación en el aula mediante actividades manipulativas y mediadas por 
ordenador. Alambique, Didáctica de las Ciencias Experimentales, 76, 17-27.

Domènech-Casal, J. (2015). Una secuencia didáctica de modelización, indagación y creación del conocimiento científico en torno a la deriva continental y la tectónica de placas. Revista Eureka sobre Enseñanza y Divulgación de las Ciencias, 12(1), 186-197. doi:

10.25267/Rev_Eureka_ensen_divulg_cienc.2015.v12.11.13

Domènech-Casal, J. (2016). Proyecto C3: indagación científica, lengua y contextos en la ESO. Aula de Secundaria, 19, 15-19.

Domènech-Casal, J. (2017). Propuesta de un marco para la secuenciación didáctica de Controversias Socio-Científicas. Estudio con dos actividades alrededor de la genética. Revista Eureka sobre Enseñanza y Divulgación de las Ciencias 14(3), 601-620. doi:

10.25267/Rev_Eureka_ensen_divulg_cienc.2017.v14.i3.07

Domènech-Casal, J. (2018). Concepciones de alumnado de secundaria sobre energía. Una experiencia de Aprendizaje Basado en Proyectos con globos aerostáticos. Enseñanza de las Ciencias, 36(2), 191-213. doi: 10.5565/rev/ensciencias.2462

Domènech-Casal, J. (2019a). Aprenentatge Basat en Projectes, Treballs Pràctics i Controvèrsies. 28 propostes $i$ reflexions per a ensenyar Ciències. Rosa Sensat: Barcelona.

Domènech-Casal, J. (2019b). Apuntes lingüísticos para el tránsito a la competencia científica. Leer para indagar en el aula de ciencias. Didacticae, Revista de Investigación en Didácticas Específicas, 5, 8598. doi: 10.1344/did.2019.5.85-98

Domènech-Casal, J. y Ruiz-España, N. (2016). De l'epiteli de ceba a la indagació. Un marc per a construir pràctiques investigadores cap a la Competència Científica. Revista Ciències 32, 12-22.

España E. y Prieto T. (2010). Problemas socio-científicos y enseñanza-aprendizaje de las ciencias. Investigación en la escuela, 71, 17-24. doi: 10.12795/IE.2010.i71.02

Farró, L., Lope, S., Marbà, A. y Oliveras, B. (2015). Les Controvèrsies Sòcio-Científiques com a contextos d'aprenentatge i comunicació a l'aula. Anàlisi crítica de la informació i habilitats comunicatives. Revista Ciències, 30, 39-46.

Ferrés-Gurt, C., Domènech-Casal, J. (2018). Dialogue and Linguistic scaffolds as tools to help students making investigable questions. XII Conferencia de Investigadores Europeos sobre Didáctica de la Biología - ERIDOB 2018.

Frayer, D., Frederick, W. C. y Klausmeier, H. J. (1969). A Schema for Testing the Level of Cognitive Mastery. Madison, WI: Wisconsin Center for Education Research.

Hernández, L. y Hernández, C. (2011). La expresión oral y escrita como proceso clave en el aprendizaje de las ciencias. Didáctica de las ciencias experimentales y sociales, 25, 213- 222.

Hodson, D. (1994). Hacia un enfoque más crítico del trabajo en el laboratorio. Enseñanza de las Ciencias, 12(3), 299-313.

Jiménez-Aleixandre, M.P. (2010). 10 Ideas clave. Competencias en argumentación y uso de pruebas. Barcelona, Graó.

Kolstø S. D. (2001). Scientific Literacy for Citizenship: Tools for Dealing with the Science Dimension of Controversial Socioscientific Issues. Science Education, 85(3), 291-310. doi: 10.1002/sce.1011

Lemke, J. L. (1997). Aprender a hablar ciencia. Lenguaje, aprendiaje y valores. Barcelona: Paidós.

Llewellyn, D. (2005). Teaching high school science through inquiry: A case study approach. Corwin Press \& NSTA Press.

Lope, S., Farró, L. (2018). Cartas conversacionales para aprender a debatir. Alambique, didáctica de las Ciencias Experimentales, 91, 49-55.

Márquez, C. y Pedreira, M. (2005). Dialogar sobre lo essencial: una propuesta de trabajo en classe de ciencias. Alambique, didáctica de las ciencias experimentales, 44, 105-112. 
Martín, M. J. (2013) . Hablar ciencia: si no lo puedo explicar, no lo entiendo. Revista Eureka sobre Enseñanza y Divulgación de las Ciencias, 10(3), 291-306. doi: 10.25267/Rev_Eureka_ensen_divulg_cienc.2013.v10.i3.01

Ripoll, J.C., Chasco, C. y Azcárate, J. (2013). Mejora de la redacción de textos argumentativos mediante estrategias autorreguladas. Pulso, 36, 175-187.

Sadler, T. D., Zeidler, D. L. (2005) Patterns of Informal Reasoning in the Context of Socioscientific Decision Making. Journal of Research in Science Teaching, 42, 112-138. doi: 10.1002/tea.20042

Sanmartí N. (coord.) (2003). Aprendre ciències tot aprenent a escriure Ciència. Barcelona: Ed 62.

Sanmartí, N. (2016). Trabajo por proyectos: ¿Filosofía o metodología? Cuadernos de Pedagogía, 472, 4446.

Sanmartí, N., Burgoa, B. y Nuño, T. (2011). ¿Por qué el alumnado tiene dificultad para utilitzar sus conocimientos científicos escolares en situaciones cotidianas? Alambique, Didáctica de las Ciencias Experimentales, 67, 62-69.

Sanmartí, N., Izquierdo, M. y García, P. (1999). Hablar y escribir, una condición necesaria para aprender ciencias. Cuadernos de pedagogía, 281, 54-58.

Sanmartí, N. Márquez, C. (2012). Enseñar a plantear preguntas investigables. Alambique, Didáctica de las Ciencias Experimentales, 70, 27-36.

Solbes, J., Ruiz, J.J., Furió, C. (2010). Debates y argumentación en las clases de física y química. Alambique, Didáctica de las Ciencias Experimentales , 63, 65-75.

Toulmin, S. E., Rieke, R. D. y Janik, A. (1984). An introduction to reasoning. New York London: Macmillan.

Trinidad, O. (2010). Producción de argumentaciones escritas en las clases de física. Alambique, Didáctica de las Ciencias Experimentales, 63, 50-56.

Trujillo, F. (coord) (2015). Proyectos lingüísticos de centro. Monográfico Julio 2015. Cuadernos de Pedagogía, 485.

Vygotsky, L. (2010). Pensamiento y lenguaje. Buenos Aires: La Pléyade.

Vilà, M. y Castellà, J.M., (2012). Argumentar y debatir con más de 25 en clase. Cuadernos de pedagogía, $423,55-60$.

Young, D.B., Tamir, P. (1977). Finding out what students know. Science Teacher, 44(6), 27-28.

\section{Información sobre los autores}

Autor: Jordi Domènech Casal

Institución: Institut de Secundària Marta Estrada (Granollers), Grupo LIEC (Departament de Didàctica de les Matemàtiques i les Ciències Experimentals). Universitat Autònoma de Barcelona Email: jdomen44@xtec.cat 


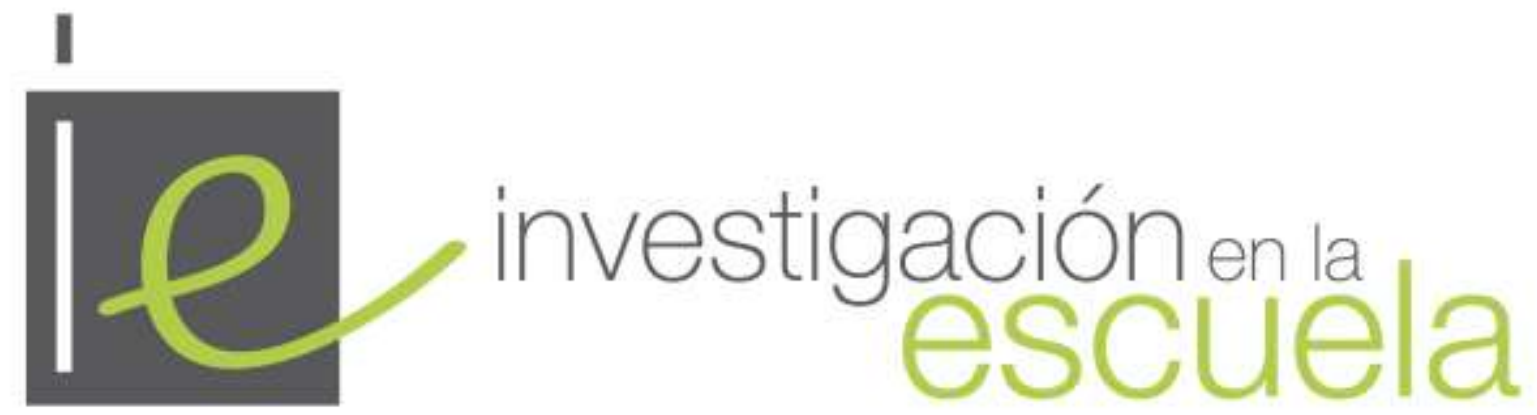

Revista académica evaluada por pares y de acceso abierto

Número 97

30 de abril de 2019

ISSN 2443-9991

\section{(c)}

SOMERIGHISRESERVEDLOS/as lectores/as pueden copiar, mostrar, y distribuir este artículo, siempre y cuando se de crédito y atribución al autor/es y a Investigación en la Escuela, se distribuya con propósitos no-comerciales, no se altere o transforme el trabajo original. Más detalles de la licencia de CreativeCommons se encuentran en http://creativecommons.org/licenses/by-nc-sa/3.0 Cualquier otro uso debe ser aprobado en conjunto por el autor/es, o Investigación en la Escuela.

ư

Revista Editada por la Universidad de Sevilla. https://editorial.us.es/es/revistainvestigacion-en-la-escuela

Contribuya con comentarios y sugerencias en la web de la revista. Por errores y sugerencias contacte a secretaria@investigacionenlaescuela.es

La revista Investigación en la Escuela desde su origen en 1987 hasta su no 87 (2015) fue editada por Díada Editora. 
